\title{
Strongly Coupled Thermo-Mechanical Casing/Abradable Model for Rotor/Stator Interactions
}

\author{
Nyssen F. ${ }^{1}$, Vadcard T. ${ }^{2}$, Piollet E. ${ }^{1}$, Batailly A. ${ }^{1}$
}

\begin{abstract}
Modern turbomachine designs feature reduced nominal clearances between rotating bladed-disks and their surrounding casings in order to improve the engine efficiency. Unavoidably, clearance reduction increases the risk of contacts between static and rotating components which may yield hazardous interaction phenomena. In this context, the deposition of an abradable coating along the casing inner surface is a common way to enhance operational safety while mitigating interaction phenomena thus allowing for tighter clearances. Nonetheless, interactions leading to unexpected wear removal phenomena between a bladed-disk and a casing with abradable coating have been observed experimentally. Beside of blade damages such as cracks resulting from high amplitudes of vibration, experimental observations included very significant temperatures increase, particularly within the abradable coating, to a point that thermo-mechanical effects may not be neglected anymore. The aim of this work is to investigate the numerical modeling of thermal effects in the abradable coating and the casing due to contact interactions. In particular, the proposed model provides insight on the sensitivity of engines to contact events when the plane had reduced tarmac times between two consecutive flights. A strongly coupled thermo-mechanical model of the casing and its abradable coating is first described. A 3D cylindrical mesh is employed, it may be decomposed in two parts: (1) along the casing contact surface, a cylindrical thermal mesh is constructed to compute the temperature elevation and heat diffusion in the three directions of space within the abradable coating, and (2) the casing itself is represented by a simplified cylindrical thermo-mechanical mesh to compute both temperature elevation and the induced deformations following temperature changes. This 3D hybrid mesh is combined with a mechanical mesh of the abradable layer, dedicated to wear modeling and the computation of normal and tangential contact forces following blade/abradable coating impacts. The heat flux resulting from contact events is related to the friction forces and only heat transfer by conduction is considered in this work. In order to reduce computational times, the time integration procedure is twofold: the explicit time integration scheme featuring reduced time steps required for contact treatment is combined with a larger time step time integration scheme used for the casing thermo-mechanical model. An extensive validation procedure is carried out from a numerical standpoint, it underlines the convergence of the model with respect to time and space parameters.
\end{abstract}

Keywords

thermo-mechanics; casing; abradable coating; rotor/stator interactions; contact; wear

1 - Department of Mechanical Engineering, École Polytechnique de Montréal, P.O. Box 6079, Succ. Centre-Ville, Montréal, Québec, Canada H3C 3A7

2 - Ecole Centrale de Lyon, 36 Avenue Guy de Collongue, 69134 Écully, France 


\title{
Modèle thermo-mécanique avec couplage fort du carter et de l'abradable pour les interactions rotor/stator
}

\author{
Nyssen F. ${ }^{1}$, Vadcard T. ${ }^{2}$, Piollet E. ${ }^{1}$, Batailly A. ${ }^{1}$
}

\begin{abstract}
Résumé
Les conceptions de turbomachines modernes présentent des jeux nominaux réduits entre les disques aubagés tournants et leurs carters environnants afin d'améliorer l'efficacité du moteur. Inévitablement, la réduction des jeux augmente le risque de contacts entre les composants statiques et tournants, qui peuvent mener à des phénomènes d'interaction dangereux. Dans ce contexte, le dépôt d'un revêtement abradable sur la surface intérieure du carter est une manière usuelle d'améliorer la sécurité en fonctionnement en atténuant les phénomènes d'interaction, et donc permettant des jeux réduits. Néanmoins, des interactions entre un disque aubagé et un carter avec un revêtement abradable menant à des phénomènes d'usure inattendue ont été observées expérimentalement. Hormis les dommages d'aubes tels que les fissurations résultant de grandes amplitudes de vibration, les observations expérimentales incluent une augmentation très significative des températures, particulièrement dans le revêtement abradable, à tel point que les effets thermo-mécaniques ne pourraient plus être négligés. Le but de ce travail est d'investiguer la modélisation numérique des effets thermiques dans le revêtement abradable et le carter suite des interactions de contact. En particulier, le modèle proposé fournit un aperçu de la sensibilité des moteurs aux évènements de contact quand l'avion a un temps réduit sur le tarmac entre deux vols consécutifs. Un modèle thermo-mécanique fortement couplé du carter et de son revêtement abradable est premièrement décrit. Un maillage cylindrique 3D est utilisé, il peut être décomposé en deux parties : (1) le long de la surface du carter, un maillage thermique cylindrique est construit pour calculer l'élévation de température et la diffusion de la chaleur dans les trois directions de l'espace dans la couche abradable, et (2) le carter lui-même est représenté par un maillage thermo-mécanique simplifié cylindrique pour calculer l'élévation de température et les déformations induites suite aux changements de températures. Ce maillage 3D hybride est combiné avec un maillage mécanique du revêtement abradable, dédié à la modélisation de l'usure et au calcul des forces de contact normales et tangentielles suite aux impacts aube/abradable. Le flux de chaleur résultant des contacts est relié aux forces de frottement, et des transferts de chaleur par conduction uniquement sont considéré dans ce travail. Pour réduire les temps de calcul, la procédure d'intégration temporelle est double : un schéma d'intégration temporelle explicite ayant des pas de temps réduits requis pour le traitement du contact est combiné avec un schéma d'intégration temporelle avec des pas de temps plus grands utilisé pour le modèle thermo-mécanique du carter. Une procédure de validation extensive est menée d'un point de vue numérique, soulignant la convergence du modèle avec les paramètres temporels et spatiaux.
\end{abstract}

Mots-clés

thermo-mécanique; casing; abradable; interactions rotor/stator; contact; usure

1 - Département de génie mécanique, École Polytechnique de Montréal, P.O. Box 6079, Succ. Centre-Ville, Montréal, Québec, Canada H3C 3A7

2 - Ecole Centrale de Lyon, 36 Avenue Guy de Collongue, 69134 Ecully, France 


\section{INTRODUCTION}

The constant need for increased aircraft engine overall efficiency is both driven by economic and environmental constraints. There are two main avenues for improving current engine designs: using lighter materials and reducing operating clearances between rotating and static components. Reduction of operating clearances is particularly critical for compressor stages where it mitigates aerodynamic losses that are detrimental to the flow compression rate. As a counterpart, clearance reduction inevitably yields more frequent structural contacts between engine components due to any relative motion stemming from thermal expansion or manoeuvre load for instance. For this reason, the blade-tip/casing contact interface has been the subject of several research works over the last decade [1, 2, 3, 4, 5, 6]. Beside of very high relative linear speeds, the intricacy of this contact interface is related to the frequent use of abradable coatings deposited along the casing surfaces in order to aim zero clearance: the liner acts as a sacrificial material that is worn out during the engine first rotation cycles so that operating clearances are minimal [7, 8, 9, 10]. In certain conditions however, interaction phenomena may arise involving both the liner and the rotating blades. As the blades rotate, undesired vibrations may yield contacts. Depending on the blades angular speed, synchronous vibrations may then feature growing amplitudes: as the liner is worn out, blades have more room to vibrate thus yielding higher wear and so on.

These phenomena have been both observed experimentally and predicted numerically [11]. Predictive numerical strategies must accurately account for unilateral contact constraints, abradable coating wear, centrifugal effects and potentially gyroscopic effects when orbiting motions are simulated. As of now, very limited attention has been paid to thermal aspects [12]. References [13, 14] focus on thermo-mechanical reduced order models and on time integration scheme for localized blade heating following contact events. However, observations made on several experimental set-ups underlined the very high temperatures measured in the vicinity of contact areas, be it by thermal probes on the outer surface of the casing [11, 15] or by infrared cameras [16]. Several observations made on full scale experimental set-ups have also revealed physical phenomena that may only be explained by considering extreme temperatures around contact areas: local modification of the rotor or stator color due to extreme heat [17], grooving patterns evidenced within the abradable coating [18, 19] as well as material transfer phenomena [20] (from the liner to the blade or vice-versa). Based on these observations, it appears that increasing the fidelity of numerical predictions now requires to accurately predict temperature levels and to account for a strong thermo-mechanical coupling.

The presented work relies on the assumption that thermal effects are critical for the understanding of rotor/stator interactions in that: (1) they locally modify the abradable coating mechanical properties thus yielding heterogeneous contact areas along the casing circumference and, (2) they lead to a thermal gradient on the casing that deforms it and favors the appearing of privileged contact areas along the casing circumference. Contrary to what is often assumed in the literature, privileged contact areas are not randomly located on the casing since casing fixation points directly impact the casing shape under thermal gradient.

More precisely, this papers introduces a strongly coupled 3D thermo-mechanical finite element model of a simplified (cylindrical) casing in which rotates a low-pressure compressor blade. As a first approximation, it is assumed that the interaction involves a single blade and that the disk dynamics may be negligible: the blade is clamped at its root. Also, and in agreement with experimental observations, the casing is insensitive to contact forces: it may only be deformed due to thermal effects.

The first section of the article details the numerical modeling of rotor/stator contact interactions and of the strongly coupled thermo-mechanical model of the abradable layer and casing. In the second section, an extensive validation is carried out to underline space and time convergence of the proposed model. In the third section, the numerical modeling strategy is applied on an industrial blade to analyze the impact of the thermal effects on the casing expansion and on the blade response.

\section{MODELING}

As mentioned above, interactions of interest essentially involve a single blade within a casing that may only be deformed due to thermal gradients resulting from repeated blade-tip/abradable contact. The modeling of each of these components: blade, abradable coating wear and casing is detailed in this section with an emphasis on the 
strongly coupled thermo-mechanical model of the casing.

\section{Blade}

The equation of motion to be solved for the blade is:

$$
\mathbf{M} \ddot{\mathbf{u}}+\mathbf{D} \dot{\mathbf{u}}+\mathbf{K}(\Omega) \mathbf{u}+\mathbf{F}_{\mathrm{c}}(\mathbf{u})=\mathbf{F}_{\mathrm{e}}
$$

where $\mathbf{M}, \mathbf{D}$ and $\mathbf{K}$ are respectively the mass, damping and stiffness matrices of the blade finite element model. For the sake of computational efficiency, a reduced order model (ROM) of the blade is built using a modified Craig-Bampton procedure that accounts for centrifugal stiffening thus explaining the dependence of the stiffness matrix with respect to the angular speed $\Omega$. This reduction method advantageously yields a mixed reduced set of coordinates in which a few physical degrees of freedom (dof) are retained-these dof are located along the blade-tip - for contact management. The number of retained nodes at the blade-tip is noted $N^{b}$. Nonlinear contact forces $\mathbf{F}_{\mathrm{c}}(\mathbf{u})$ are applied on the blade-tip only and $\mathbf{F}_{e}$ represent any potential external forcing, it is here set to zero. The blade temperature is assumed constant along the simulation. Experimental observations [11] underlined that the blade's heated areas are very localized along its tip, it is here assumed that thermal effects on the blade do not significantly impact its dynamics.

\section{Abradable layer and contact forces}

Abradable elements are modeled by 1D radial plastic elements evenly spaced around the casing circumference. A plastic constitutive law is employed for wear management [21]. This simplified wear law allows to dynamically update clearances during the simulation. This wear law yields an estimate of contact forces that are used: (1) for the prediction of the blade displacements and, (2) for the computation of the heat flux applied on the casing.

The contact forces between the blade and the abradable layer is computed using:

$$
\mathbf{F}_{\mathrm{c}}(\mathbf{u})=\sum_{i} A_{i} \sigma_{i}
$$

where $A_{i}$ corresponds to the cross-section area of an abradable element $i$, and $\sigma_{i}$ is the normal stress within each abradable element $i$. The computation of the latter is detailed in reference [21]. In the case where blade's vibrations are large enough to yield local full removal of the coating, contact occurs between the blade and the casing, and the contact forces are are computed using the forward increment Lagrange multiplier method [22]. The central finite difference explicit time integration scheme is used to compute blade displacements at each time step $n$. Predicted blade displacements, noted $\mathbf{u}_{n+1}^{\mathrm{p}}$ are computed as follows:

$$
\mathbf{u}_{n+1}^{\mathrm{p}}=\mathbf{A} \mathbf{u}_{n}+\mathbf{B} \mathbf{u}_{n-1}
$$

with:

$$
\begin{aligned}
& \mathbf{A}=\left[\frac{\mathbf{M}}{h^{2}}+\frac{\mathbf{D}}{2 h}\right]^{-1}\left[\frac{2 \mathbf{M}}{h^{2}}-\mathbf{K}\right] \\
& \mathbf{B}=\left[\frac{\mathbf{M}}{h^{2}}+\frac{\mathbf{D}}{2 h}\right]^{-1}\left[\frac{\mathbf{D}}{2 h}-\frac{\mathbf{M}}{h^{2}}\right]
\end{aligned}
$$

where $h$ is the time step of the time integration procedure. Should a penetration within the casing be detected, predicted displacements are then corrected:

$$
\mathbf{u}_{n+1}=\mathbf{u}_{n+1}^{\mathrm{p}}+\mathbf{C} \mathbf{F}_{\mathrm{c}}\left(\mathbf{u}_{n+1}\right)
$$

where:

$$
\mathbf{C}=\left[\frac{\mathbf{M}}{h^{2}}+\frac{\mathbf{D}}{2 h}\right]^{-1}
$$




\section{Casing}

The presented casing thermo-mechanical model combines a 3D thermal mesh for the abradable coating and a 3D thermo-mechanical mesh for the surrounding simplified casing, see Fig. 1. It should be noticed that the proposed methodology is inherently compatible with the use of more realistic industrial models of the casing that could be reduced by means of a Rational Craig-Hale reduction method [23]. As a first step however, it is here validated on a simplified cylindrical casing.

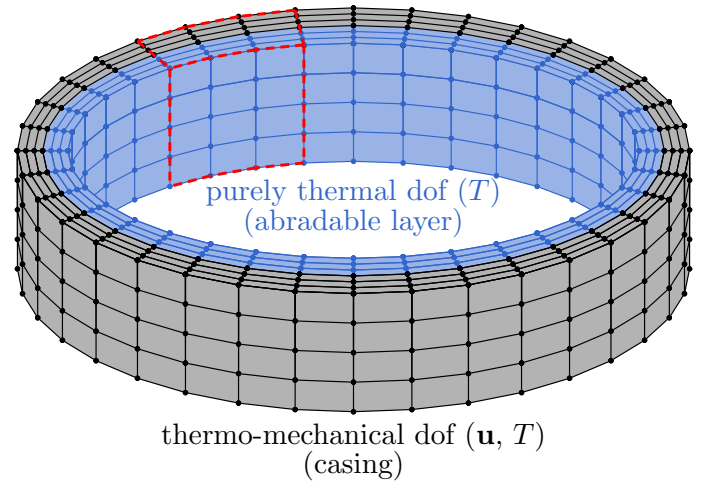

Figure 1. Thermo-mechanical finite element mesh

\section{Finite element model}

The employed thermo-mechanical finite element mesh consists in a cylindrical mesh that can be decomposed in two parts, as illustrated in Fig. 1: (1) a thermal mesh with one thermal dof per node for the abradable layer (in blue) and, (2) a thermo-mechanical mesh with four dof per node (three displacements and one temperature) for the casing (in gray). Degrees of freedom of the system are grouped in the vector $\mathbf{q}$ such as:

$$
\mathbf{q}=\left[\begin{array}{l}
\boldsymbol{\theta} \\
\mathbf{u}
\end{array}\right]
$$

where $\boldsymbol{\theta}$ contains all nodal temperatures and $\mathbf{u}$ the casing displacements. The equation of motion reads:

$$
\underbrace{\left[\begin{array}{cc}
\mathbf{0} & \mathbf{0} \\
\mathbf{0} & \mathbf{M}^{u u}
\end{array}\right]}_{\mathbf{M}_{T}} \ddot{\mathbf{q}}+\underbrace{\left[\begin{array}{cc}
\mathbf{C}^{\theta \theta} & \mathbf{C}^{\theta u} \\
\mathbf{0} & \mathbf{0}
\end{array}\right]}_{\mathbf{C}_{T}} \dot{\mathbf{q}}+\underbrace{\left[\begin{array}{cc}
\mathbf{K}^{\theta \theta} & \mathbf{0} \\
-\mathbf{K}^{u \theta} & \mathbf{K}^{u u}
\end{array}\right]}_{\mathbf{K}_{T}} \mathbf{q}=\underbrace{\left[\begin{array}{c}
\mathbf{Q} \\
\mathbf{0}
\end{array}\right]}_{\mathbf{F}_{T}}
$$

where $\mathbf{M}^{u u}$ and $\mathbf{K}^{u u}$ correspond to the structural mass and stiffness matrices of the casing, $\mathbf{C}^{\theta \theta}$ and $\mathbf{K}^{\theta \theta}$ denote the thermal conductivity and capacity matrices of the casing and the abradable layer, and $\mathbf{C}^{\theta u}$ and $\mathbf{K}^{u \theta}$ are the coupling matrices. $\mathbf{Q}$ contains the heat flux.

The thermo-mechanical mesh used for the abradable coating is distinct from the mechanical mesh mentioned above for wear computation. As a matter of fact, each mesh must have specific features and relies on distinct types of finite elements: while a fine mechanical mesh is required for the computation of contact forces (with $N$ elements along the circumference and $N^{b}$ elements along the axial direction), converged temperatures may be obtained with a coarser mesh. The link between the two meshes is depicted in Fig. 2, in which each bar element (of length $h_{a}$ ) of the mechanical mesh is represented in red and the thermo-mechanical mesh in blue and black. Discretization parameters of the thermo-mechanical mesh are: $n_{c}=\frac{N}{N_{c}}$ along the circumferential direction, $n_{a}=\frac{N^{b}}{N_{a}}$ along the axial direction and $n_{r}$ along the radial direction. 


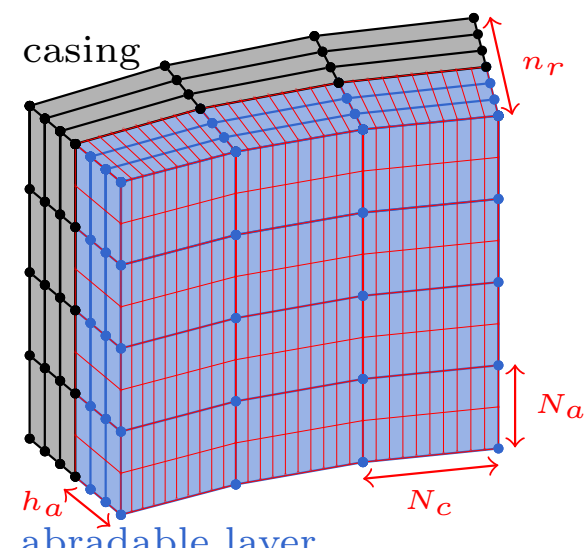

Figure 2. abradable meshes: (๑) mechanical, (•) thermo-mechanical

\section{Time integration}

The equation of motion given in Eq. (9) is solved using a Newmark integration scheme distinct from the time integration scheme used for predicting the blade's displacements. While very efficient for contact treatment, the latter is indeed unstable for the solution of thermo-mechanical problems. In addition, the different time scales associated with mechanical and thermal phenomena justify a much larger time step $h^{\star}$ may be used for the solution of Eq. (9), thus reducing the computation cost of the proposed model. $N_{t}$ defines the relation between the two time steps: $h^{\star}=N_{t} h$, the thermo-mechanical problem is only solved every $N_{t}$ mechanical time steps:

$$
\mathbf{q}_{k+1}=\mathbf{A}^{\star} \mathbf{q}_{k}+\mathbf{B}^{\star} \mathbf{q}_{k-1}+\mathbf{C}^{\star} \mathbf{F}_{T k}
$$

where:

$$
\begin{aligned}
& \mathbf{C}^{\star}=\left[\frac{1}{h^{\star 2}} \mathbf{M}_{\mathrm{T}}+\frac{\alpha}{h^{\star}} \mathbf{D}_{\mathrm{T}}+\frac{\beta}{2} \mathbf{K}_{\mathrm{T}}\right]^{-1} \\
& \mathbf{A}^{\star}=\mathbf{C}^{\star}\left[\frac{2}{h^{\star 2}} \mathbf{M}_{\mathrm{T}}+\frac{(2 \alpha-1)}{h^{\star}} \mathbf{D}_{\mathrm{T}}+\left(\beta-\alpha-\frac{1}{2}\right) \mathbf{K}_{\mathrm{T}}\right] \\
& \mathbf{B}^{\star}=\mathbf{C}^{\star}\left[\frac{1}{h^{\star 2}} \mathbf{M}_{\mathrm{T}}-\frac{(\alpha-1)}{h^{\star}} \mathbf{D}_{\mathrm{T}}-\left(\frac{\beta}{2}-\alpha+\frac{1}{2}\right) \mathbf{K}_{\mathrm{T}}\right]
\end{aligned}
$$

This time integration scheme is unstable for $\alpha \leq 0.5$, conditionally stable for $0.5 \leq \alpha$ and $2 \beta \leq \alpha$, and unconditionally stable for $0.5 \leq \alpha \leq 2 \beta$ [24]. An unconditionally stable scheme is chosen with $\alpha=0.6$ and $\beta=0.4$.

\section{Heat flux}

In this study, only heat conduction within the abradable layer and the casing is taken into account. The thermal flux is modeled as a surfacic heat flux provided by the blade to the abradable surface (inner surface of the cylindrical thermo-mechanical mesh). The heat flux is assumed proportional to the blade/abradable layer friction forces. Since friction forces are computed based on the mechanical mesh (mentioned above for wear computation) and a coarser discretization is used for thermo-mechanical mesh, the heat flux is distributed between the four surrounding thermal nodes. More particularly, a weighted distribution is considered, depending on the location of the impacted wear elements comparing to surrounding thermal nodes as illustrated in Fig. 3. 


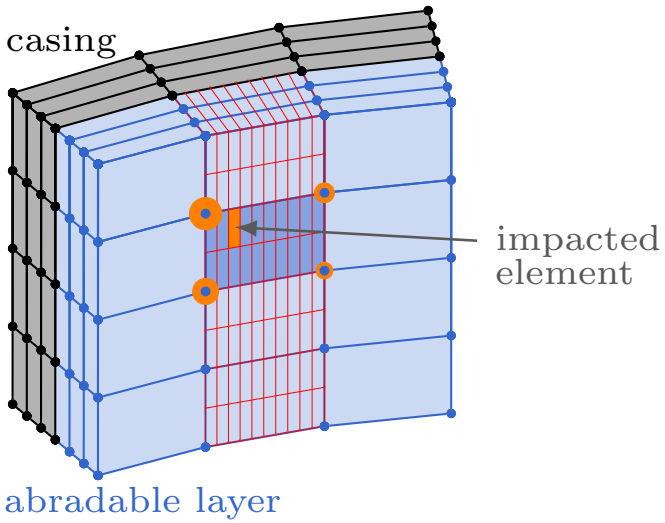

Figure 3. Weighted heat flux distribution

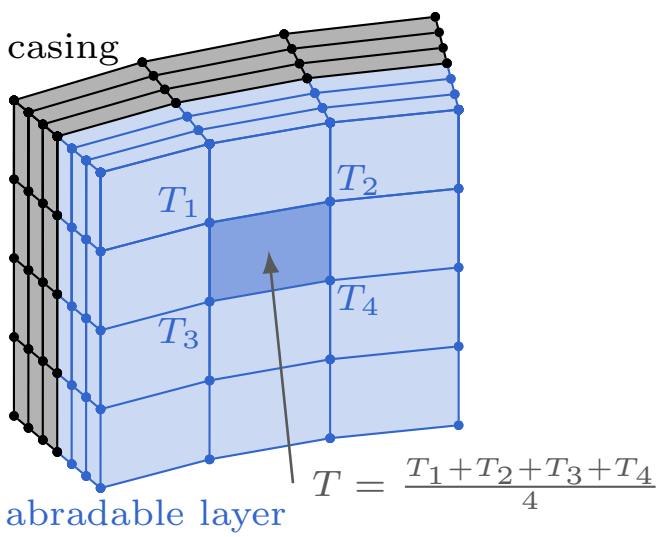

Figure 4. Temperature considered for abradable layer's elements thermal expansion

\section{Thermal expansion}

The profile of the abradable layer is evaluated using the wear mesh made of 1D-bar elements. The thermal expansion of these abradable layer elements is computed using the nodal temperatures obtained with the thermo-mechanical mesh. The mean temperature of the four surrounding nodes is used to compute the abradable layer's elements thermal expansion (as illustrated in Fig. 4). For the thermal expansion of the casing, these are directly obtained from the thermo-mechanical mesh, in which the temperature/displacement coupling is taken into account.

\section{NUMERICAL VALIDATION}

This section details the time and space convergence of the proposed numerical strategy for a given test case.

\section{Test case}

The test case consists in a single low-pressure compressor blade rotating at constant angular speed. The associated finite element mesh is shown in Fig. 5. Eight boundary nodes are retained within the ROM for contact management. The surrounding casing is initially circular. The casing is clamped at four nodes evenly spaced along its circumference $\left(0^{\circ}, 90^{\circ}, 180^{\circ}\right.$ and $\left.270^{\circ}\right)$, in front of the blade's trailing edge (TE), as illustrated in Fig. 6 . The blade displacement due to centrifugal loads does not lead to contact: a small initial clearance between the blade and the casing is considered. A uniform thermal flux is applied on the abradable layer in order to represent an increasing temperature after the engine has started. Subsequent thermal expansion of the thermo-mechanical model of the casing with abradable coating is responsible for contact initiation. Simulations are carried out over 10 blade revolutions. 


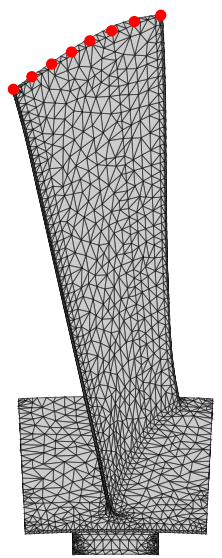

Figure 5. Blade finite element model with retained nodes

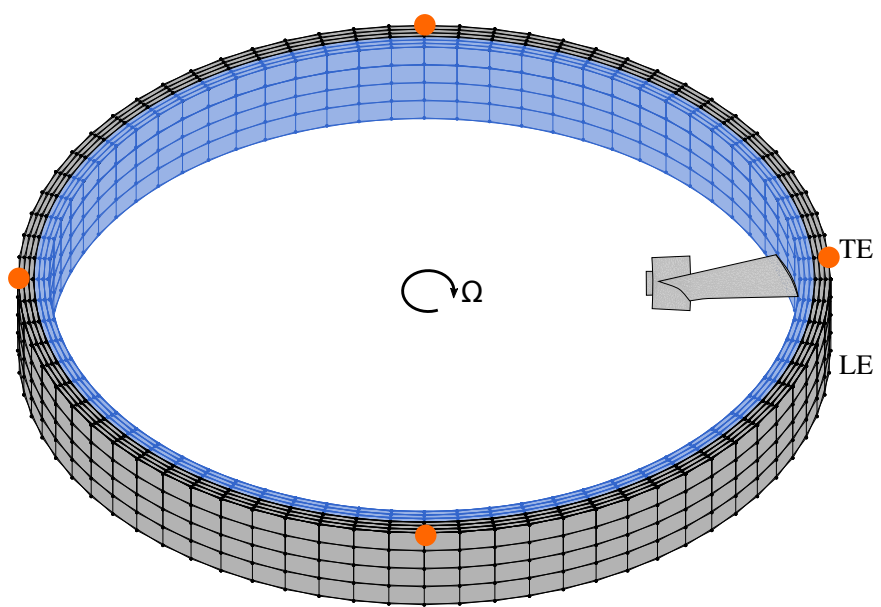

Figure 6. Clamping conditions of the thermo-mechanical model: (•) four equally spaced nodes at the trailing edge (TE) side

Convergence is checked for all relevant quantities including blade's displacements, wear patterns within the abradable coating, casing displacements and temperatures. Presented results are essentially focused on the thermomechanical model of the casing with abradable since it is the center of the proposed developments.

\section{Time convergence}

Convergence of the simulations results with the time discretization of the thermo-mechanical problem is analyzed. The mechanical time step $h$ is set to $10^{-7} \mathrm{~s}$ for all simulations. The admissible time step of the thermal time integration scheme depends on the maximal eigenfrequency of the thermo-mechanical mesh. In the present case, the maximum thermal time step $h^{\star}$ is $10^{-6} \mathrm{~s}$ thus corresponding to $N_{t}=10$. The casing radial deformation and the maximum temperature increase at the leading edge side at the end of the simulation, along the boundary between the abradable layer and the casing, are depicted in Figs. 7a and 7b for different values of $N_{t}$. Computation times required for each value of $N_{t}$ are given in Fig. 7c. Computations are carried out on a standard i7-processor PC.

The casing deforms between the clamped points, as can be seen in Fig. 7a. Because a uniform heat flux is applied on the abradable layer, its temperature increases and the thermal expansion increases slightly its length. The abradable layer undergoes thermal expansion as well because of the temperature increases. Figure 7b shows that the main temperature increases in due to the applied uniform heat flux, but four areas of higher temperature appears. These are due to contact events between the blade and the abradable layer. For both displacements and temperature degrees of freedom, results superimposed for all $N_{t}$ values. Since the computation times decreases with 


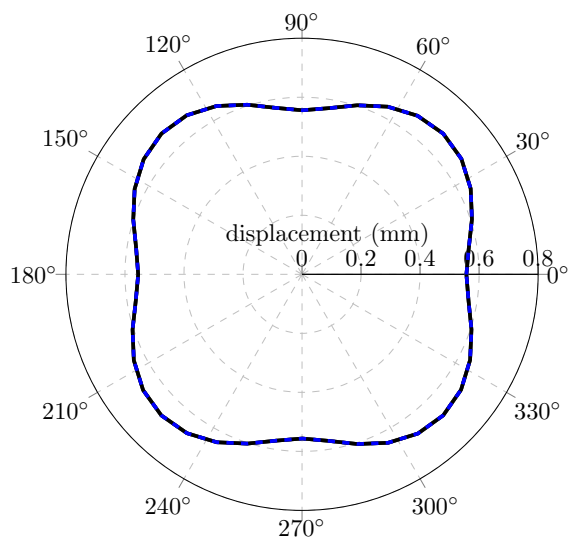

(a) displacement

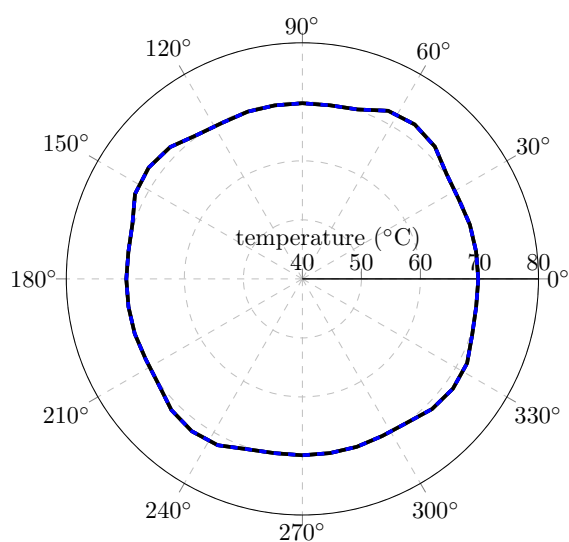

(b) temperature

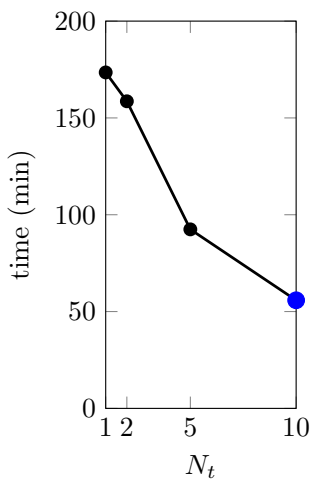

(c) computation times

Figure 7. Time convergence: $((-)) N_{t}=1,((-)) N_{t}=2,((-)) N_{t}=5,((-\mathbf{- ~ - ~})) N_{t}=10$

\section{Space convergence}

In this section, the space convergence of temperatures and casing displacements is analyzed as a function of the number of mesh elements in the circumferential (denoted $\left.n_{c}\right)$, axial $\left(n_{a}\right)$ and radial $\left(n_{r}\right)$ directions.

The number of mechanical abradable elements is kept constant and equal to 10000 to ensure that results are converged. The obtained results are given in Figures 8, 9 and 10 for the circumferential, axial and radial directions respectively. More particularly, as for the time convergence analysis, the displacements at the interface between the casing and the abradable layer on the leading edge side and the temperature increase at the same nodes at the end of the simulation are drawn. The computation times for each simulation are given in Figure 8c, 9c and 10c respectively. Since computation times increases with the number of elements for the three space directions, a compromise between results accuracy and computation times will be made for each direction.

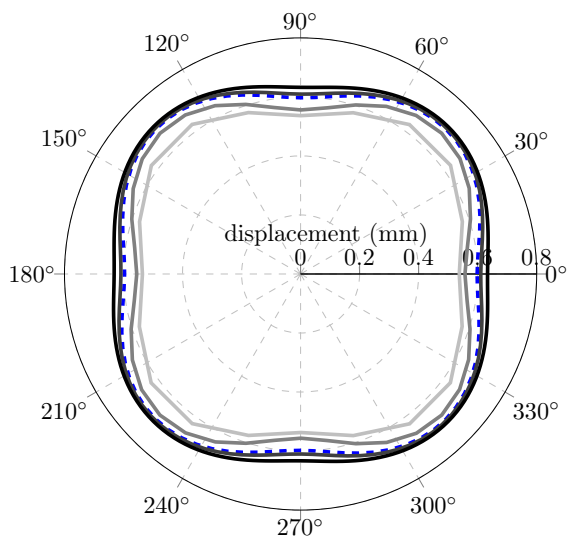

(a) displacement

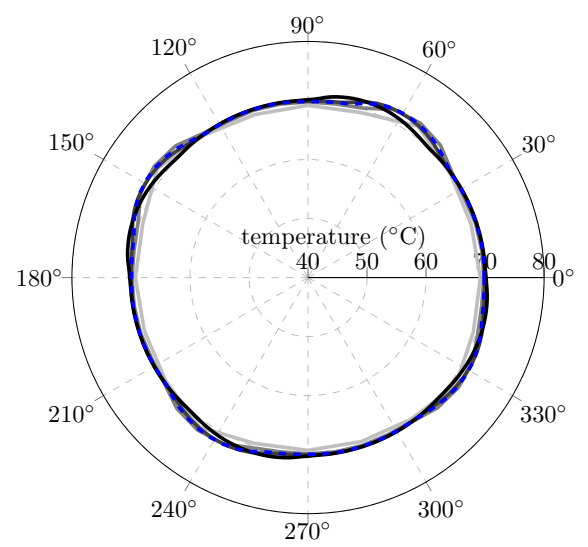

(b) temperature

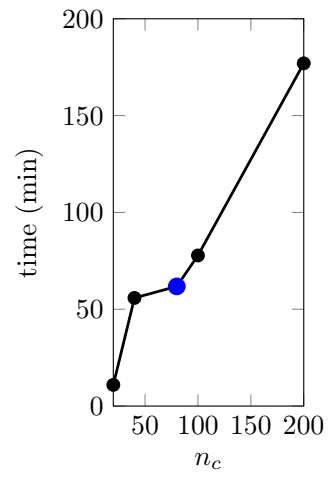

(c) computation times

Figure 8. Convergence with mesh discretization in circumferential direction: $((-)) 500$ elements, $((-)) 100$ elements, $((--\mathbf{l})) 80$ elements, $((-)) 40$ elements, $((-)) 20$ elements

When looking at results related to the circumferential direction, see Fig. 8, it can be observed that displacements degrees of freedom are more sensitive to the space discretization than temperatures. But since the computation time 


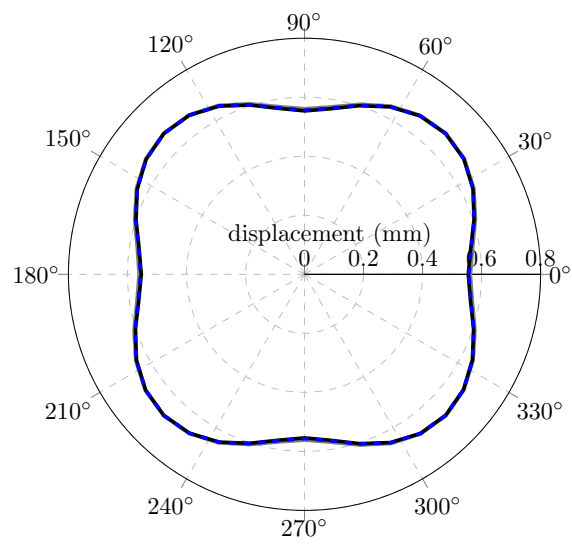

(a) displacement

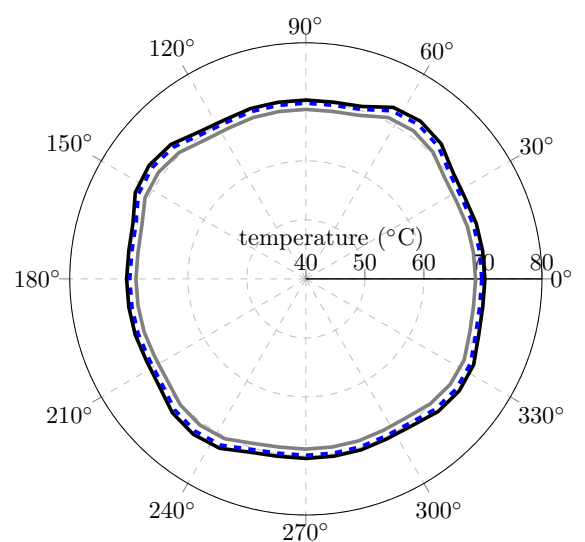

(b) temperature

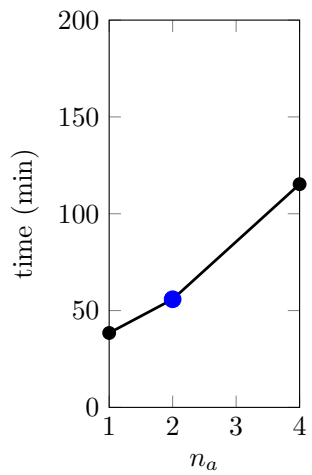

(c) computation times

Figure 9. Convergence with mesh discretization in axial direction: $((\boldsymbol{\square})) 4$ elements, $((-\mathbf{-}-)) 2$ elements, $((\square)) 1$ element

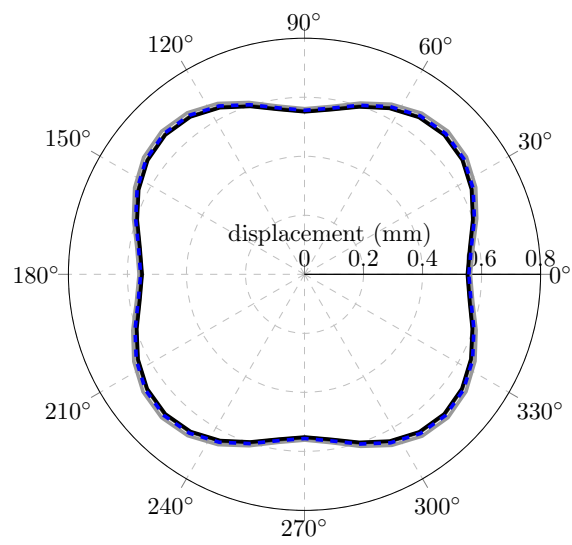

(a) displacement

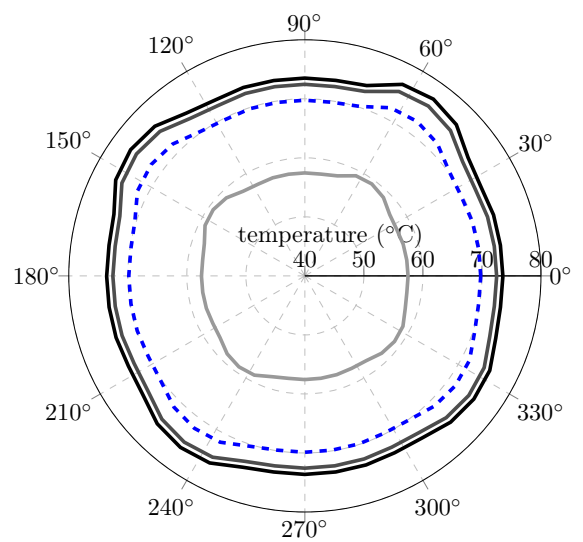

(b) temperature

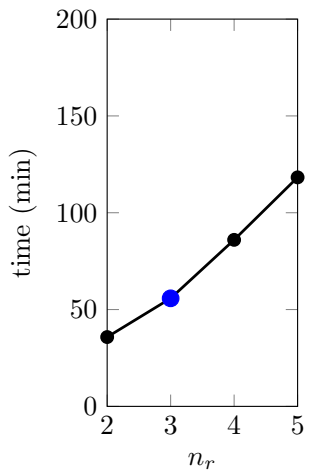

(c) computation times

Figure 10. Convergence with mesh discretization in radial direction: $((\boldsymbol{\square})) 10$ elements, $((\boldsymbol{L})) 8$ elements, $((\mathbf{-}-\mathbf{-})) 6$ elements, $((-)) 4$ elements

increases with the number of finite elements, see Fig. $8 \mathrm{c}, 80$ thermal elements are considered in the following. This value appears as a good compromise between results accuracy and computation times.

With respect to the results obtained in the axial direction plotted in Fig. 9, temperatures for $n_{a}=2,4$ and 8 elements are perfectly superimposed. The distance between the leading and trailing edge is small and does not require a fine discretization. In the following, 2 axial elements are used. It seems likely that this parameter is highly dependent on the type of blade considered for simulations. Indeed, a blade featuring a longer chord such as, for instance, a fan blade or an impeller blade, will probably require larger values of $n_{a}$.

Finally, for the radial direction, the mesh is refined for both the casing and the abradable layer. Thus, there are $2 n_{r}$ elements along the radial direction. The following values are considered: $n_{r}=2,3,4$ and 5 elements are used. Displacements are accurately predicted for all cases. However, it is noticeable that temperature convergence does require a high value of $n_{r}$. In the following, 6 elements are kept which appears as a good compromise between results accuracy and computation times. 


\section{CASE STUDY}

It has been observed that contact events are likely to occur following aircraft taxi phases. From the engine standpoint, taxi phases are periods of time during which it cools down. Accordingly, a very specific thermal gradient is applied on the structure as the warm air tends to go up. This section focuses on blade/casing contact simulations following the application of such thermal conditions in order to provide a better understanding of the blade/casing configuration following taxi phases. Temperatures and heat flux are all normalized for the sake of confidentiality. Though it relies on an industrial blade, the proposed case study is purely phenomenological, experimental data will be further required for finer predictions on casing industrial models.

\section{Interaction scenario}

The low-pressure compressor blade considered for the convergence analysis is also used for this case study, see Fig. 5 . The surrounding casing is initially perfectly circular. It is fixed at three clamping points in agreement with typical engine configurations. Clamping points are evenly spaced along the circumferential direction, they are located at $30^{\circ}, 150^{\circ}$ and $270^{\circ}$ on the external surface of the casing, in front of the trailing edge of the blade. In order to numerically reproduce the rising heat flux that generate a heat unbalance within the engine at rest, a positive heat flux is applied at the top of the thermo-mechanical mesh. This heat flux is pictured in Fig. 11a. Since the

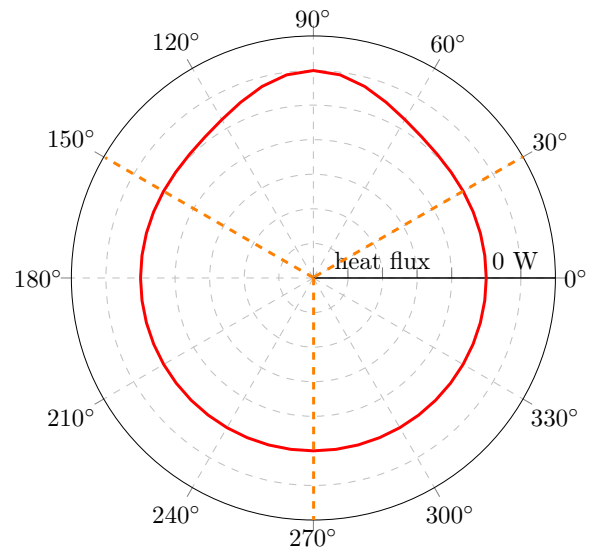

(a) Applied heat flux

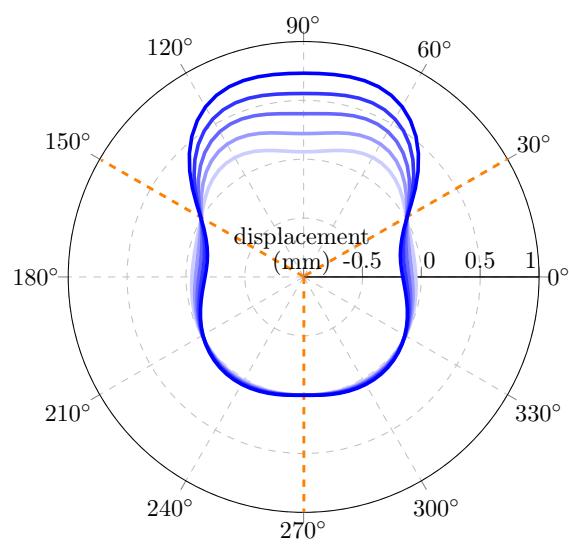

(b) Casing deformation

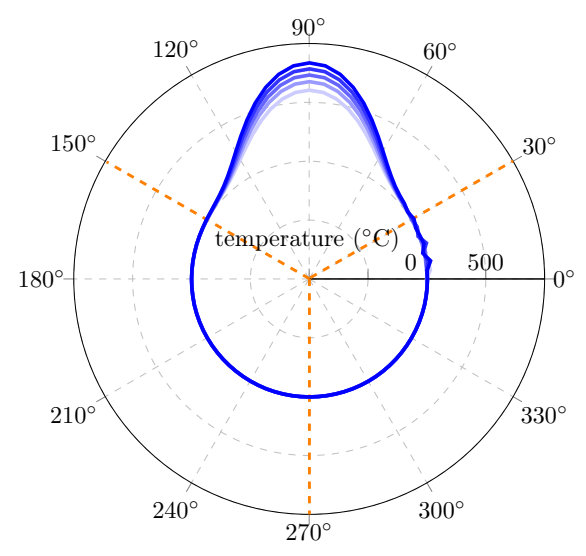

(c) Temperature profile

Figure 11. Applied heat flux with $((---))$ clamping conditions, and casing and temperature profiles for different time steps: $((\square)) t=125.6 \mathrm{~ms},((-)) t=251.1 \mathrm{~ms},((-)) t=376.8 \mathrm{~ms},((-)) t=502.4 \mathrm{~ms},((\square)) t=628 \mathrm{~ms}$

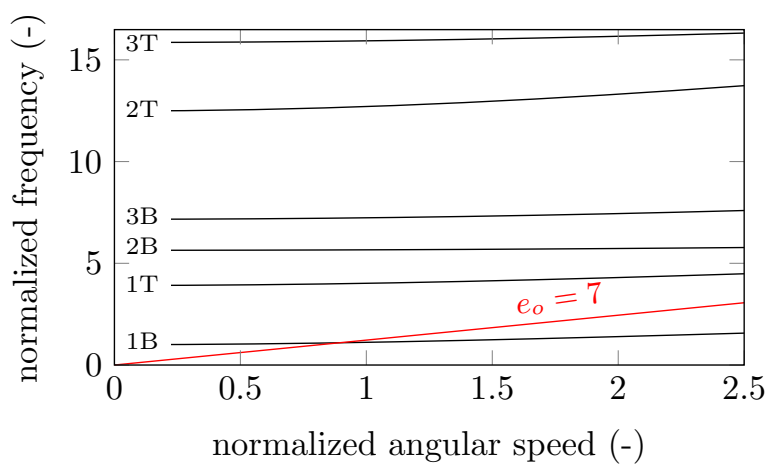

Figure 12. Campbell diagram

applied flux is largely distributed along the casing circumference, reduction methods developed in [13] for localized 
heatings cannot be applied. The chosen blade angular speed corresponds to the crossing between its first bending mode and the 7 th engine order $\left(e_{o}\right)$, which is below the engine nominal speed. This particular interaction is chosen because it has been previously experimentally observed [11] and belongs to the nominal angular speed of the engine. The Campbell diagram of the corresponding blade is given in Fig. 12. The simulation is carried out on 20 blade revolutions. Previous numerical simulations have indeed underlined that divergent rubbing interactions may be predicted over such short amount of time.

\section{Numerical observations}

Figure 11b shows the casing deformation in front of the blade trailing edge along the inner surface of the casing for different time steps of the simulation. At $90^{\circ}$, the positive heat flux induces a thermal expansion of the casing, that moves away the casing. Overall, the casing deformation yields two privileged contact areas with the blade tip since its radius is locally reduced for $\theta \simeq 0^{\circ}$ and $\theta=180^{\circ}$. The maximum clearance reduction along the circumference is about $0.2 \mathrm{~mm}$ for $\theta \simeq 10^{\circ}$. Figure 11c shows the temperature profile at the inner surface of the casing for different time steps of the simulation at the trailing edge. The temperature increases in the area of the applied heat flux (around $90^{\circ}$ ). Temperature increases due to friction between the blade and the abradable layer at $0^{\circ}$ and $180^{\circ}$ are negligible in this case after 20 blade revolutions, only minor peaks are visible for $\theta \simeq 15^{\circ}$.

Abradable wear profiles predicted along the casing circumference at the leading edge and the trailing edge are depicted in Fig. 13. The abradable layer and casing profiles are plotted without thermal expansion, considering the casing at ambient temperature. It is noticeable that the $0.2 \mathrm{~mm}$ clearance reduction translates into a maximum wear of more than $1 \mathrm{~mm}$ during the 20 blade revolutions. This clearly underlines the rise of very high amplitude vibrations on the blade, which is consistent with previous experimental observations [11]. Seven wear lobes are predicted in front of the blade trailing edge. The green dotted lines in Fig. 13 shows the abradable layer profile taking into account its thermal expansion at the end of the simulation. At both leading and trailing edges, a thermal expansion of the abradable layer can be evidenced around $90^{\circ}$ since the temperature is higher in this area. The red dotted lines correspond to the abradable layer profile with both abradable layer's thermal expansion and casing deformation at the end of the simulation. At the leading edge, the casing deformation at $90^{\circ}$ explains that the abradable layer is worn only at the beginning of the simulation. At $0^{\circ}$ and $180^{\circ}$, the increased wear level is due to the fact that blade/casing clearance is locally reduced. At the trailing edge, the casing thermal expansion explains the smaller depth of wear at $0^{\circ}$.

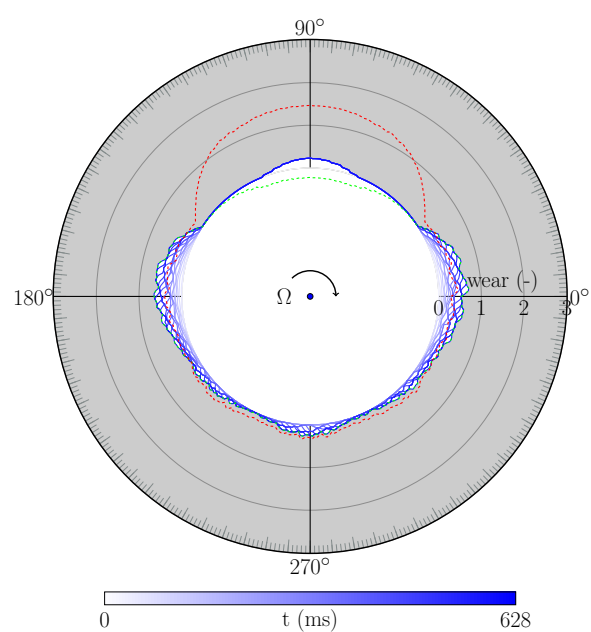

(a) LE

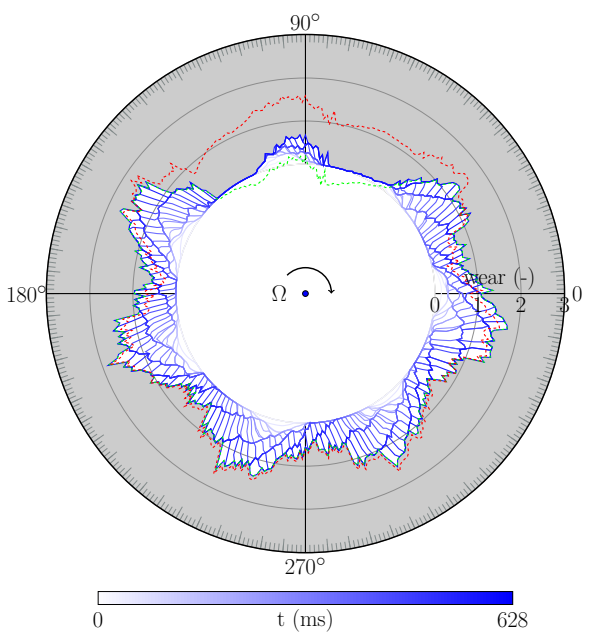

(b) $\mathrm{TE}$

Figure 13. Wear profile for different time steps

The thermal expansion of the casing is found to be sufficient to initiate an interaction along the first blade's 
first bending mode. Time evolution of the wear profile underlines a rotation of the wear lobes which signifies that the blade's dynamics is not perfectly synchronous at the considered angular speed. Nonetheless, amplitudes of vibration increase over time. Leading and trailing edges radial displacements are depicted in Fig. 14 where the growing amplitude of vibrations over the 20 blade revolutions hint for a potential diverging motion.

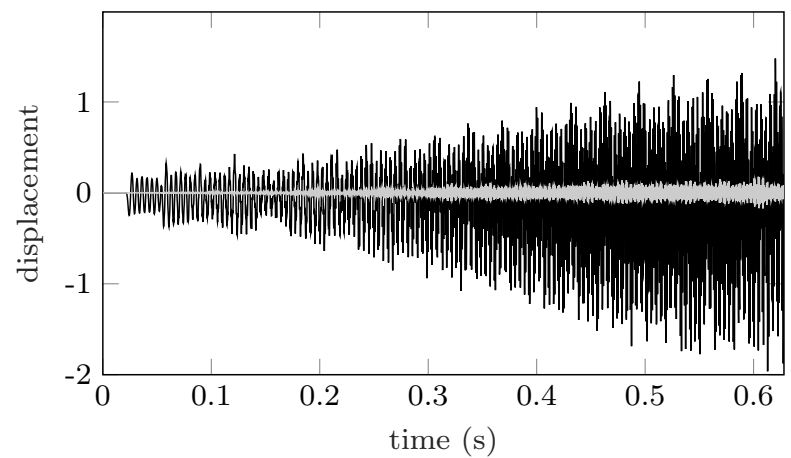

Figure 14. Blade displacement: $((-))$ trailing edge, $((-))$ leading edge

The spectrograms of the blade's displacement at the leading and trailing edges are depicted in Fig. 15. At the beginning of the simulation, following the very first contacts, the first free vibration mode of the blade is dominant. Over time, the contribution of modes $2 \mathrm{~B}$ and $3 \mathrm{~B}$ (respectively second and third bending modes) increases to a point where other modes' contributions are negligible.

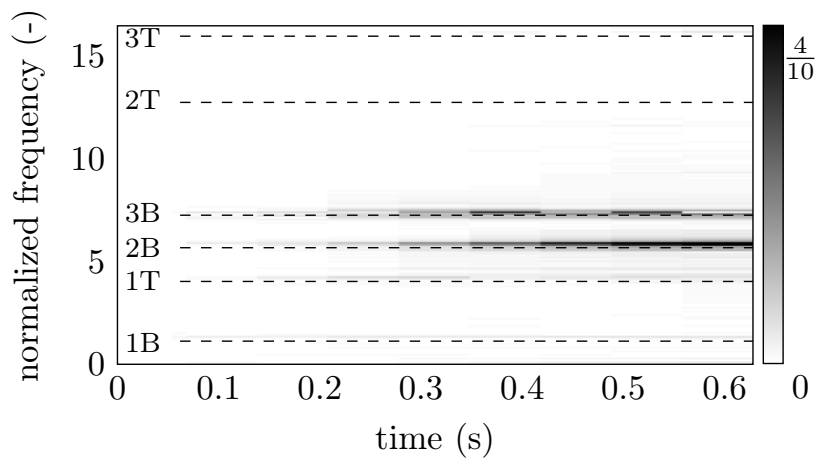

(a) LE

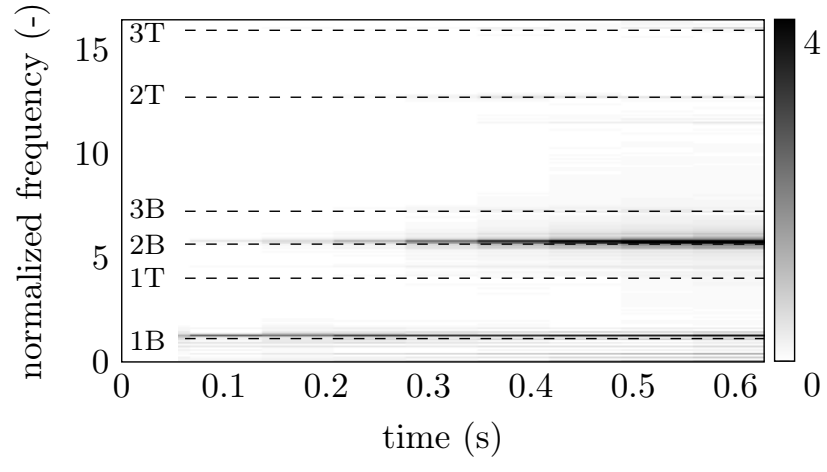

(b) TE

Figure 15. Spectrogram of the blade displacement

\section{Variation of the angular speed}

Figure 16 shows the abradable layer's wear profile at the leading and trailing edge sides for different engine angular speeds around the previously investigated value. Wear depth is pictured by means of a color code from white- no wear - to black corresponding to full abradable coating removal. For each angular speed, simulation are carried out over 20 blade revolutions. At $90^{\circ}$, white areas appear on the two wear maps: the abradable layer is not worn due to the casing thermal expansion. Different interactions can be identified in Figure 16b. Around $\Omega=0.9,8$ wear lobes are observed: there are 8 dark areas vertically aligned. The angular speed investigated in the previous section $(\Omega=1)$ corresponds to the arisal of the 7 engine order interaction. Indeed, from that point, and for higher angular speeds $(\Omega \in[1,1.1]) 7$ wear lobes are evidenced. The spread of the seven lobe wear pattern throughout this angular speed range underlines the robustness of the interaction. Going back to Fig. 13, it is noticeable that wear 
lobes rotate counterclockwise over time, thus hinting a non perfectly synchronous blade vibration. Interestingly, the same observation can be made when looking at the evolution of the deeper lobes angular location with respect to the angular speed $\Omega$ in Fig. 16. For these reasons, it seems likely that the predicted interaction considering a constant angular speed may also exist assuming a sufficiently low acceleration of the rotor. Therefore, numerical results suggest that potential blade damage may occur during engine acceleration following a short taxi phase.

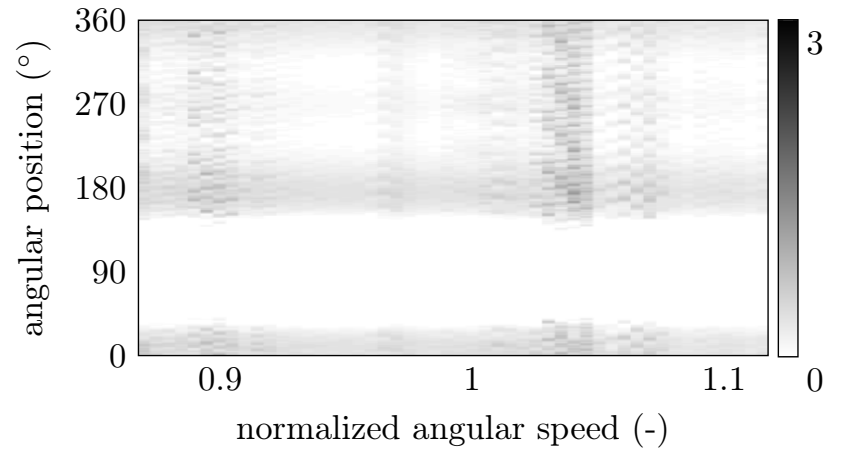

(a) LE

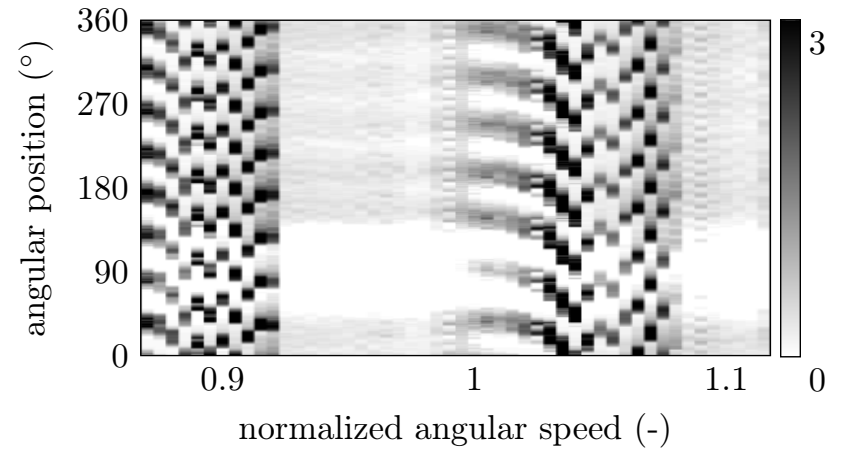

(b) $\mathrm{TE}$

Figure 16. Wear maps

\section{Partial conclusion and perspectives}

Based on the proposed thermo-mechanical model, this case study underlines that in certain conditions, dissymmetric thermal loadings on the casing may give birth to undesirable interaction phenomena. While the rotor is not supposed to operate at the investigated angular speed, it will definitely cross this point as it reaches nominal speed. This is where the time scale of the witnessed interaction matters. As only 20 revolutions yield significant wear on the casing, it seems possible to damage the blade as the engine accelerates. In order to assess the blade damage, detailed stress analyses will be carried out in future works. As a preliminary step, Fig. 17 shows the resulting stress field within the blade close to the end of the simulation (at $t=514.6 \mathrm{~ms}$ ) where $\sigma_{Y}$ is the blade yield stress.
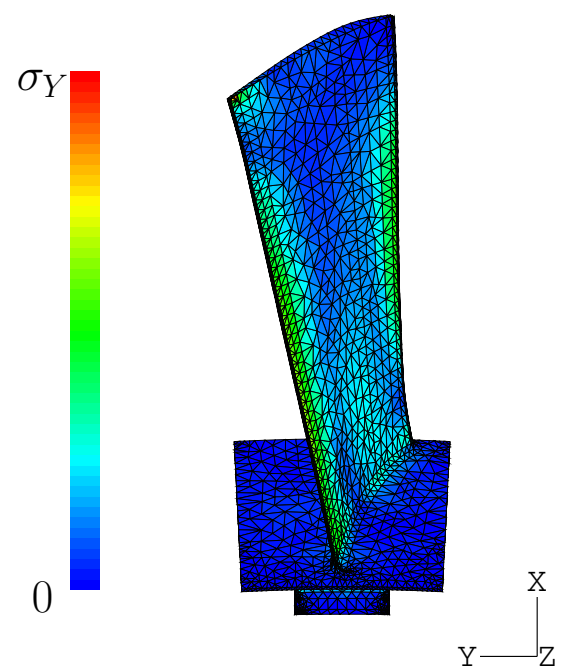

Figure 17. Stress field within the blade at $t=514.6 \mathrm{~ms}$ 


\section{CONCLUSION}

A thermo-mechanical model combining a simplified casing and an abradable layer is proposed in this work. It aims at accurately capturing temperature increases as well as thermally induced deformations within the stator of an aircraft engine following blade/casing contact events. Time and space convergences are checked in order to assess the robustness of the proposed methodology. As a first application of this model, a blade/casing case study following aircraft taxi phases is considered. It is evidenced that the application of a dissymmetric thermal gradient, assumed to be representative of thermal conditions within a cooling down engine, leads to a contact configuration that is propitious to interaction phenomena. Indeed, thermal expansions of the casing are responsible for privileged contact areas that may be required to help synchronize blade vibrations at the vicinity of interaction angular speeds.

This work has been performed on a simplified casing geometry. A possible extension of the proposed model would be to consider a realistic casing model and build a reduced order model in order to replace structural matrices of the cylinder model by the reduced matrices of the realistic casing. Work is also in progress in order to enhance the code structure in order to reduce further computation times. Finally, a calibration of the proposed model with respect to experimental data is ongoing.

\section{Acknowledgments}

This research was supported by the Natural Sciences and Engineering Research Council of Canada (NSERC). The authors are also grateful to the industrial partner for supporting this project, Safran Aircraft Engines.

\section{References}

[1] Legrand, M., Pierre, C., Cartraud, P., and Lombard, J. P., 2009. "Two-dimensional modeling of an aircraft engine structural bladed disk-casing modal interaction". Journal of Sound and Vibration, 319(1-2), pp. 366-391. doi: 10.1016/j.jsv.2008.06.019 - oai: hal-00328186v2.

[2] Padova, C., Dunn, M. G., Barton, J., Turner, K., Turner, A., and DiTommaso, D., 2011. "Casing treatment and blade-tip configuration effects on controlled gas turbine blade tip/shroud rubs at engine conditions". Journal of Turbomachinery, 133(1), p. 011016. doi: 10.1115/1.4000539.

[3] Turner, K. E., Dunn, M., and Padova, C., 2012. "Airfoil Deflection Characteristics During Rub Events". Journal of Turbomachinery, 134(1), p. 011018. doi: 10.1115/1.4003257.

[4] Jacquet-Richardet, G., Torkhani, M., Cartraud, P., Thouverez, F., Nouri Baranger, T., Herran, M., Gibert, C., Baguet, S., Almeida, P., and Peletan, L., 2013. "Rotor to stator contacts in turbomachines. Review and application". Mechanical Systems and Signal Processing, 40(2), pp. 401-420. doi: 10.1016/j.ymssp.2013.05.010.

[5] Parent, M.-O., Thouverez, F., and Chevillot, F., 2014. "Whole engine interaction in a bladed rotor-tostator contact". In ASME Turbo Expo 2014: Turbine Technical Conference and Exposition, pp. 1-10. doi: 10.1115/GT2014-25253.

[6] Almeida, P., Gibert, C., Thouverez, F., and Ousty, J.-P., 2015. "Numerical Analysis of Blade Disk - Casing Contact with Friction and Wear". In ASME Turbo Expo 2015: Turbine Technical Conference and Exposition. doi: 10.1115/1.4033065.

[7] Baïz, S., 2011. "Etude expérimentale du contact aube/abradable : contribution à la caractérisation mécanique des matériaux abradables et de leur interaction dynamique sur banc rotatif avec une aube". PhD thesis, Ecole Centrale de Lille. oai: tel-00605091.

[8] Sinha, S. K., 2013. "Rotordynamic analysis of asymmetric turbofan rotor due to fan blade-loss event with contactimpact rub loads". Journal of Sound and Vibration, 332(9), pp. 2253 - 2283. doi: 10.1016/j.jsv.2012.11.033.

[9] Mandard, R., 2015. "Dynamique de contact aube - revêtement abradable : identification expérimentale de la force et des mécanismes d'interaction". PhD thesis, Ecole Centrale de Lille. 
[10] Padova, C., Barton, J., Dunn, M. G., Manwaring, S., Young, G., Adams, M. J., and Adams, M., 2005. "Development of an experimental capability to produce controlled blade tip/shroud rubs at engine speed". Journal of Turbomachinery, 127(4), pp. 726-735. doi: 10.1115/1.1934429 - oai: hal-01553829.

[11] Millecamps, A., Brunel, J., Dufrénoy, P., Garcin, F., and Nucci, M., 2009. "Influence of thermal effects during blade-casing contact experiments". In Proceedings of the ASME 2009 IDETC \& CIE conference, ASME. doi: 10.1115/DETC2009-86842 - oai: hal-01223060.

[12] Nyssen, F., and Batailly, A., 2018. "Thermo-mechanical modeling of abradable coating wear in aircraft engines". Journal of Engineering for Gas Turbines and Power, 141(2), p. 021031. doi: 10.1115/1.4041647 - oai: hal-01942616.

[13] Guérin, N., Thorin, A., Thouverez, F., Legrand, M., and Almeida, P., 2018. "Thermomechanical model reduction for efficient simulations of rotor-stator contact interaction". Journal of Engineering for Gas Turbines and Power, 141(2), p. 022501. doi: 10.1115/1.4040858 - oai: hal-01223060.

[14] Thorin, A., Guérin, N., Legrand, M., Thouverez, F., and Almeida, P., 2018. "Nonsmooth thermoelastic simulations of blade-casing contact interactions". Journal of Engineering for Gas Turbines and Power, 141(2), p. 022502. doi: 10.1115/1.4040857 - oai: hal-01713919.

[15] Agrapart, Q., Dufrénoy, P., Desplanques, Y., Brunel, J.-F., and Millecamps, A., 2017. "Modélisation thermomécanique du contact aube-abradable dans les turboréacteurs". In Proceedings of the Congrès Français de Mécanique. pdf: 133795 - oai: hal-01768624.

[16] Batailly, A., Agrapart, Q., Millecamps, A., and Brunel, J.-F., 2016. "Experimental and numerical simulation of a rotor/stator interaction event within an industrial high-pressure compressor". Journal of Sound and Vibration, 375, pp. 308-331. doi: 10.1016/j.jsv.2016.03.016 - oai: hal-01342401.

[17] Kosing, O., Scharl, R., and Schmuhl, H., 2001. "Design improvements of the ej $200 \mathrm{hp} \mathrm{compressor:} \mathrm{From} \mathrm{design}$ verification engine to a future all blisk version". In ASME Turbo Expo 2001: Turbine Technical Conference and Exposition, pp. 1-6. doi: 10.1115/2001-GT-0283.

[18] Yi, M., He, J., Huang, B., and Zhou, H., 1999. "Friction and wear behaviour and abradability of abradable seal coating". Wear, 231, pp. 47-53. doi: 10.1016/S0043-1648(99)00093-9.

[19] Ma, X., and Matthews, A., 2009. "Evaluation of abradable seal coating mechanical properties". Wear, 267(9-10), pp. 1501-1510. doi: 110.1016/j.wear.2009.03.044.

[20] Delebarre, C., Wagner, V., Paris, J.-Y., Dessein, G., Denape, J., and Santanach, J. G., 2017. "Tribological characterization of a labyrinth-abradable interaction in a turbo engine application". Wear, 370-371, pp. 29-38. doi: 10.1016/j.wear.2016.11.007 - oai: hal-01758599.

[21] Legrand, M., Batailly, A., and Pierre, C., 2012. "Numerical Investigation of Abradable Coating Removal in Aircraft Engines Through Plastic Constitutive Law". Journal of Computational and Nonlinear Dynamics, 7(1), p. 011010. doi: 10.1115/1.4004951 - oai: hal-00627526.

[22] Carpenter, N. J., Taylor, R. L., and Katona, M. G., 1991. "Lagrange Constraints for Transient Finite Element Surface Contact". International Journal for Numerical Methods in Engineering, 32(1), pp. 103-128. doi: 0.1002/nme.1620320107 - oai: hal-01389918.

[23] Guérin, N., Thouverez, F., Gibert, C., Legrand, M., and Almeida, P., 2017. "Thermomechanical component mode synthesis for blade casing interaction prediction". In Proceedings of the ASME Turbo Expo 2017 conference, GT2017-64342. doi: 10.1115/GT2017-64342 - oai: hal-01569918.

[24] Newmark, N., 1959. "A method of computation for structural dynamics". Proceedings of the American Society of Civil Engineers, Journal of Engineering Mechanics, 85(EM3), pp. 67-94. 